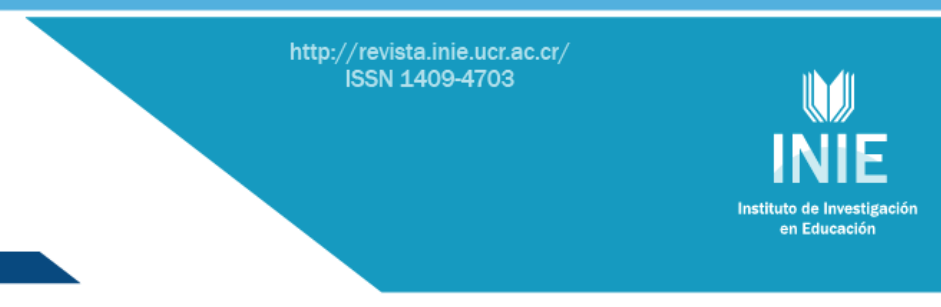

\title{
ESTRATEGIAS DIDÁCTICAS MEDIADAS CON TIC EN UN CURSO DE EXPRESIÓN ORAL FRANCESA \\ DIDACTIC STRATEGIES MEDIATED BY ICT IN A FRENCH ORAL EXPRESSION COURSE
}

\author{
Volumen 14, Número 2 \\ Mayo - Agosto \\ pp. 1-30
}

Este número se publicó el 30 de mayo de 2014

Kuok-Wa Chao Chao

Revista indizada en REDALYC, SCIELO

Revista distribuida en las bases de datos:

CATÁLOGO DE LATINDEX, IRESIE, CLASE, DIALNET, DOAJ, E-REVIST@S, SHERPA/ROMEO, QUALIS, MIAR

Revista registrada en los directorios:

ULRICH'S, REDIE, RINACE, OEI, MAESTROTECA, PREAL, $\underline{\text { CLASCO }}$ 


\title{
ESTRATEGIAS DIDÁCTICAS MEDIADAS CON TIC EN UN CURSO DE EXPRESIÓN ORAL FRANCESA \\ DIDACTIC STRATEGIES MEDIATED BY ICT IN A FRENCH ORAL EXPRESSION COURSE
}

\author{
Kuok-Wa Chao Chao'
}

\begin{abstract}
Resumen: Este artículo presenta los resultados de una investigación acerca del uso de las estrategias mediadas por tecnología de la información y comunicación (TIC) con las herramientas Exelearning, Aula Virtual de Apoyo de Metics y Audacity, en el curso de Expresión Oral I, específicamente en el módulo de Fonética de las carreras de Bachillerato en Francés y Bachillerato en la Enseñanza del Francés, durante el primer semestre de 2013, en la Universidad de Costa Rica. Esta investigación de tipo cualitativo se llevó a cabo con estudiantes de dicho curso, que respondieron un instrumento sobre el uso de las TIC en el aprendizaje de la fonética. Como principal conclusión, el estudiantado señala que estas herramientas facilitaron y mejoraron su aprendizaje de la fonética, tanto teórico y práctico, en el francés como lengua extranjera. Además, aporta un cambio al esquema tradicional de la enseñanza de la fonética, haciendo que sea el estudiantado el principal actor del proceso de formación.
\end{abstract}

Palabras clave: FRANCÉS, FONÉTICA, ESTRATEGIAS DIDÁCTICAS, TIC, COSTA RICA

\begin{abstract}
This article presents the results of an investigation on the use of strategies mediated by tools such as ICT (Information Technology and Communication), eXeLearning, Virtual Classroom Support given by METICS and Audacity, in the course entitled Oral Expression I, specifically in the phonetics' module which is part of both Bachelor in French and Bachelor in the Teaching of French careers, during the first semester 2013 at the University of Costa Rica. This qualitative study was conducted with the students of the course who answered a questionnaire on the use of ICT in learning phonics. As main conclusion, the students said that these tools provided and improved their learning of phonics both theoretical and practical in the field of French as a foreign language. Also it brings a change to the traditional scheme of phonics instruction, being the student a leading actor in his or her own training process.
\end{abstract}

Key words: FRENCH, PHONETICS, DIDACTIC STRATEGIES, ICT, COSTA RICA

\footnotetext{
${ }^{1}$ Docente en la Escuela de Lenguas Modernas de la Universidad de Costa Rica. Maestría en Lingüística de la Universidad de Costa Rica.
}

Dirección electrónica: kuok.chao@ucr.ac.cr

Artículo recibido: 14 de noviembre, 2013

Devuelto para corrección: 5 de febrero, 2014

Aprobado: 3 de marzo, 2014 


\section{Introducción}

Las tecnologías de la información y de la comunicación (TIC) forman ya parte de la vida de gran cantidad de seres humanos y están presentes en todos los ámbitos de la sociedad. Esto ha provocado una profunda transformación en muchos aspectos sociales, económicos, políticos, educativos. Es claro que son una oportunidad importante para modernizar los sistemas educativos y reactualizar las prácticas pedagógicas en diferentes niveles. Por supuesto, la educación superior no escapa a esta modernización y reactualización.

Ya desde mediados del siglo XX, ha habido un interés creciente en implementar la tecnología en la educación, ya que las TIC son un elemento esencial en los nuevos espacios y contextos de interacción entre los individuos, por el hecho de que crean entornos de aprendizaje que ponen a disposición del estudiantado, amplitud de información actualizada. Allí reside el valor de reconfigurar estos nuevos escenarios educativos que cambian rápida y constantemente, por los avances tecnológicos.

En cuanto a la enseñanza del francés, las TIC han acompañado a los aprendices en su proceso de formación, tal como lo menciona Beauné (2011):

para la rama del Francés como Lengua Extranjera, se puede constatar que los usos de EAO (Enseñanza asistida por computadoras) se basan generalmente en los principios didácticos del Método Audio-Oral (MAO) que existe desde el final de la Segunda Guerra Mundial o en el método Estructura Global Audiovisual 19 (SGAV) promovido desde los años 60 (Traducción libre del autor) ${ }^{2}$.

La aparición de las TIC ha contribuido a acercar a los aprendices a contextos reales de utilización de una lengua extrajera, como el uso de chat, de foros, entre otros, en donde la persona puede tener contacto con hablantes nativos de la lengua y así practicarla, o tener acceso a una formación continua y la actualización de conocimientos, ya que se puede encontrar diferentes tipos de información o sitios en Internet, para practicar la lengua o encontrar explicaciones sobre reglas gramaticales, pronunciación, ejercicios en línea, etc., así como hallar cursos en línea de una lengua extranjera, y de esa manera se puede desarrollar su autonomía.

\footnotetext{
${ }^{2}$ Cita original : "pour le domaine du FLE, on constate que les usages de type EAO peuvent s'accorder aux principes didactiques de la Méthode Audio-Orale (MAO) datant de la fin de la Seconde Guerre mondiale ou de celle nommée Structuro-Globale-Audio-Visuelle19 (SGAV) promue dès les années 60" (2011, p.10).
} 
Además, las TIC se han convertido en realidad notoria y necesaria para una parte de la sociedad actual. Por lo tanto, el profesorado de una lengua extrajera, como es el caso del francés, debe adaptarse a esta nueva situación sin ningún temor, tomando en cuenta estas 2 consideraciones: "el alumnado lleva ventaja, porque para él una computadora es simplemente un juguete tan familiar como el teléfono celular que teclean incansablemente" y esto parece “dejar en desventaja al profesorado que debe adaptarse a una nueva y desconocida situación, pero puede tener una lectura muy ventajosa si éste consigue entender que siendo la computadora, como se ha dicho, un juguete, tiene una multiplicidad de usos en el aula que contarán siempre con una aceptación decisiva en el alumnado" (Álvarez, 2004, p. 498). Entonces, al fomentar el uso de TIC en clase, se podría emplear otros recursos que contribuyan al aprendizaje de una segunda lengua y no limitarse solo al libro de texto o al cuaderno de ejercicio.

Este artículo presenta los resultados obtenidos del análisis de las experiencias del estudiantado con la utilización de aplicaciones como Exelearning, Audacity y Aula Virtual para el aprendizaje de la fonética en el curso de Expresión Oral I, LM-2232, como medio de innovación en los programas de Bachillerato en Francés y Bachillerato en la Enseñanza del Francés.

\section{Marco teórico referencial}

\subsection{Las tecnologías de la información y de la comunicación (TIC)}

Autores como Adell (1991), Basque (2005), Chacin (2006), Kone/Tago (2007), Ferro y otros (2009) han aportado definiciones acerca de lo que son las tecnologías de la información y de la comunicación (TIC).

Para este artículo se define las tecnologías de la información y de la comunicación, como un conjunto de elementos y herramientas computacionales e informáticas que permiten el acceso, la producción, el almacenamiento, el procesamiento, la síntesis, la recuperación y la presentación de la información, utilizando imágenes, sonido y datos contenidos dentro de un sistema de información y comunicación integrado e interconectado, y estas tecnologías pueden conllevar a producir cambios y transformaciones en la forma de crear los conocimientos y de relacionarse entre los seres humanos. Además, pueden generar consecuencias sobre la forma de percibir el mundo y las creencias que tienen los individuos, produciendo transformaciones en la vida social y cotidiana, ya que muchas veces estas 
relaciones no se gestan de manera presencial, sino a distancia y rompiendo las barreras espacio-temporales.

Las TIC están afectando también los procesos educativos generados en el seno de la sociedad. En lo que concierne al uso pedagógico que aportan al proceso de enseñanza y aprendizaje, contribuyen sustancialmente, ya que pueden promover una mejor relación entre profesorado y alumnado, desarrollar dinámicas de cooperación entre el alumnado favoreciendo un aprendizaje más colaborativo, fomentar las técnicas activas de aprendizaje, al promover en el estudiantado una participación activa, permitir los procesos de retroalimentación y respetar la diversidad de formas de aprender.

Al concebir las TIC, probablemente la educación no fue pensada como principal aplicación, sino que se han ido desarrollando algunas con este fin, y se han ido incorporando gracias al papel que juegan las TIC en la sociedad de la información. Además, las TIC se presentan como poderosos instrumentos para promover el proceso formativo y hacen que más personas accedan a la formación y la educación mediante la supresión de las barreras espacio-temporales. Chacin (2006, p. 6) se refiere a las tecnologías educativas que comprenden "todos aquellos medios electrónicos al servicio de la mejora de la educación y el tratamiento de la información que van surgiendo de los avances propiciados por el desarrollo y que están modificando los procesos técnicos".

Las TIC presentan muchas ventajas en el proceso formativo. Según Malagón y Frías (2008), ayudan a superar las limitaciones temporales o distancias geográficas entre docentes y educandos, haciendo desaparecer las barreras espacio-temporales, de modo que facilitan extender la formación más allá de las maneras tradicionales de la enseñanza presencial. Es así como los procesos formativos quedan abiertos y flexibles, puesto que las posibilidades educativas no se limitan únicamente en los entornos presenciales y cercanos a la realidad del estudiantado, sino que se puede encontrar cursos o propuestas de formación en entornos más lejanos y distantes. Así, las TIC ofrecen como ventaja la comodidad, ya que al no existir las barreras espacio-temporales, permitirán tener acceso todo el tiempo y en cualquier lugar, a la información y a la comunicación, sin necesidad de desplazamiento.

El mismo autor menciona como ventaja una enseñanza más personalizada e individualizada, puesto que existe la posibilidad de adaptar la información a las necesidades y características de los participantes, adecuando el proceso instructivo a las necesidades particulares de cada usuario. Además, se produce una mejora de la comunicación entre los 
participantes, por el hecho de que se procura favorecer e incrementar el intercambio de la información y la colaboración entre los individuos participantes del proceso formativo.

Malagón y Frías (2008) habla también de un acceso rápido a la información, puesto que las TIC permiten alcanzar la información velozmente, y reducen de esta manera su grado de obsolescencia, utilizando más eficientemente las fuentes informativas existentes a través de la red. De esta manera, existe una posibilidad de interactuar con la información, ya que con las TIC se produce un cambio en el proceso formativo, por el hecho de que este deja de ser una simple recepción y memorización de datos recibidos en clase, para convertirse en una búsqueda permanente, análisis y reelaboración de informaciones obtenidas en la red. Esto puede ayudar a elevar el interés y la motivación del educando, puesto que capta su atención, al ser uno de los motores del aprendizaje para incitar a la actividad y al pensamiento.

De acuerdo con Ferro et al. (2009), las TIC mejoran la eficacia educativa, ya que permiten al profesorado disponer de más tiempo para realizar otras tareas, como la estimulación del desarrollo de las facultades cognitivas superiores del estudiantado, la actualización profesional de forma fácil y rápida, la práctica sistemática mediante ejercicios autocorrectivos de refuerzo sobre técnicas instrumentales o presentación de conocimientos generales, la posibilidad de realizar actividades complementarias de apoyo al proceso formativo, proponiendo el acceso a los múltiples recursos educativos y entornos de aprendizaje (materiales didácticos digitales, Internet, entre otros).

Según Fernández (2010), una de las ventajas de las TIC es el hecho de que fomentan el trabajo cooperativo entre los individuos participantes del proceso formativo, con lo que pueden favorecer una mayor comunicación entre las partes.

De acuerdo con Perreault (2005), otra ventaja importante de las TIC es el fomento del desarrollo de habilidades transversales, ya que el estudiantado realiza aprendizajes disciplinares y tecnológicos, y al mismo tiempo otros que contribuyen al desarrollo de habilidades intelectuales como la criticidad y la resolución de problemas, y habilidades sociales como el trabajo colaborativo.

De igual manera, las TIC favorecen una mayor autonomía en el proceso formativo, puesto que el alumnado dispone de infinito número de canales y de gran cantidad de información, lo que crea una mayor independencia porque debe aprender a tomar decisiones por sí mismo. 
Por último, las TIC favorecen la creatividad y el desarrollo de la iniciativa del alumnado, al permitir la imaginación y el aprendizaje autónomo.

Sin embargo, las TIC presentan también algunas desventajas en el proceso formativo. Según Palomar (2009), pueden generar distracción y dispersión, ya que el uso que se les da los estudiantes, no siempre se enfoca al proceso formativo, sino que las pueden emplear para actividades como chatear sobre temas no relevantes, revisar el perfil en Facebook para ver actualizaciones de amigos, o fines lúdicos desvinculados con el objeto de aprendizaje programado, etc.

Otra desventaja es el hecho de que se puede encontrar información no fiable, puesto que en Internet existe un exceso de datos que no siempre son fidedignos. Además, se puede encontrar informaciones parciales, obsoletas, equivocadas o que no han sido verificadas por expertos en la materia.

Por eso, Palomar (2009) habla de la posibilidad de que se den aprendizajes incompletos y superficiales, ya que la libre interacción de los alumnos con estos materiales, no siempre de calidad y con frecuencia descontextualizados, puede proporcionar aprendizajes incompletos con visiones de la realidad simplistas y poco profundas. Esta situación se produce a menudo por el hecho de que el estudiantado puede conseguir mucha información en un lapso corto, sin que se genere un proceso formativo y una consolidación del aprendizaje, sino que puede ocasionarse solo una simple acumulación de datos.

De acuerdo con Cladellas y Castelló (2010), una de las desventajas de las TIC es la pereza, ya que existe la tendencia de buscar todo por Internet y esto puede producir que las personas se descuiden de la creación, la innovación y la reflexión personal e individual, por el hecho de que pueden copiar solamente lo que se encuentra en Internet. Además, esta situación puede causar aislamiento, puesto que el uso constante de las herramientas de TIC puede aislar al estudiantado de otras formas comunicativas como el contacto o la sociabilidad con quienes nos rodean.

Otra desventaja es el costo de algunas herramientas de TIC, ya que no todas se pueden conseguir de manera gratuita o a un costo bajo, sino que existen herramientas como las pizarras interactivas o las computadoras, con un costo alto, y no todo el mundo o los centros educativos pueden adquirirlas.

Por último, otra gran desventaja de las TIC es la ansiedad, debido a la continua interacción ante la computadora. 
A pesar de la existencia de desventajas para el uso de las TIC en el proceso formativo, no se debe olvidar todos los aportes que pueden brindar a la educación, ya que en la sociedad actual de la información y del conocimiento, donde existe una gran variedad de medios y rapidez de la difusión de los datos, pueden ser unas aliadas importantes para permitir que los participantes tengan acceso y también vean todas las ventajas que les pueden ofrecer, como la rupturas de las barreras espacio-temporales, la interactividad, la comodidad, la comunicación abierta y flexible, el desarrollo de las habilidades transversales, entre otras. Por eso conviene aprovechar estas bondades que las TIC ofrecen para el proceso enseñanza-aprendizaje, y así experimentar con ellas para encontrar sus usos más efectivos.

En el mundo actual no se puede prescindir de su uso, ya que se están integrando cada vez más a la vida cotidiana de los individuos. Por eso es necesario potenciar su uso y aprovechar todas las ventajas que ofrezcan al proceso formativo, y hacer de ellas una herramienta contundente para acompañar este proceso.

Otro punto significativo es el hecho de que se pueden contrarrestar estas desventajas cuando se integran en un marco de acción pedagógico, en donde su utilización tiene un objetivo determinado y no su empleo porque está de "moda" o porque se exija, sino para responder a una planificación previamente reflexionada y así aprovechar todas las ventajas que ofrecen al ámbito educativo.

\subsection{Exelearning}

El Exelearning es un programa de código abierto y multiplataforma para la creación de contenido web didáctico, que no requiere grandes conocimientos en edición web, ni lenguaje HTML, ni ningún otro lenguaje de programación. Los materiales creados pueden incluir textos, imágenes, videos, presentaciones, animaciones, actividades interactivas como ejercicios de elección múltiple, falso/verdadero, etc., y así obtener como resultado un contenido web que puede ser visualizado desde cualquier navegador y exportado a múltiples plataformas.

El proyecto Exelearning está financiado por el Gobierno de Nueva Zelanda y coordinado por la University of Auckland. En él participan grupos de colaboradores de todo el mundo, como es el caso del Departamento de Lenguajes y Sistemas Informáticos de la Universidad de Alicante. Una de las principales características de Exelearning es que oculta la necesidad de conocer a fondo HTML, XML o aplicaciones de publicación en la web, a menudo complicadas y cuyo uso requiere cierto adiestramiento. De esta forma se evita al usuario, 
como es el caso del docente, tener que conocer estos lenguajes de programación para implementar los contenidos.

Las herramientas que contiene Exelearning se pueden clasificar como sigue:

a. Crear elementos de presentación de contenidos como objetivos y preconocimiento.

b. Adjuntar otros elementos multimedia, como galería de imágenes, imagen ampliada, applet de Java.

c. Agregar elementos externos como artículos de Wikipedia, RSS.

d. Elaborar actividades como lectura, estudio de caso, reflexión.

e. Efectuar preguntas y juegos como actividad de espacios en blanco, pregunta falso/verdadero, pregunta de escogencia múltiple, examen SCORM.

\subsection{Audacity}

Audacity es una aplicación informática multiplataforma de código libre, que sirve de editor de grabación y de edición de sonido. También se utiliza para la conversión entre formatos de tipo audio, la importación de archivos de formato MIDI, RAW y MP3, para agregar efectos al sonido como eco, inversión, tono.

\subsection{Aula virtual de apoyo de la plataforma Mediación Virtual}

Según la Unidad de Apoyo a la Docencia Mediada con Tecnologías de la Información y la Comunicación (METICS) de la Universidad de Costa Rica (Chacón, 2012, p. 6), un aula virtual de apoyo es un tipo de curso regular en donde todas las sesiones del mismo ocurren en un entorno de aula física, o en el lugar donde de costumbre se utiliza.

Esta unidad depende de la Vicerrectoría de Docencia de la Universidad de Costa Rica y apoya a la comunidad docente por medio de:

a. Promoción y desarrollo de entornos educativos basados en el uso de TIC.

b. Desarrollo y socialización de experiencias e innovaciones pedagógicas apoyadas con TIC.

c. Apoyo a proyectos académicos que requieren alto grado de autonomía.

d. Capacitación para el desarrollo de la docencia mediada con TIC. 
El aula virtual es una herramienta que brinda posibilidades de realizar procesos de enseñanza y aprendizaje en línea. Es un entorno privado que permite administrar procesos educativos basados en un sistema de comunicación mediado por computadoras. Se puede comprender el término de aula virtual como un espacio simbólico en el que se produce la relación entre participantes, en un proceso formativo que, para interactuar entre sí y acceder a la información relevante, utilizan este sistema de comunicación mediada por computadoras.

En el caso del aula virtual de METICS, se encuentran aplicaciones para fomentar este proceso formativo en línea, tales como: foros, wiki, glosario, ejercicios en línea, diarios. Además, se puede enviar documentos como tareas, grabaciones, etc.; hallar tipos de información como materiales complementarios del curso, lecturas, programa, videos, grabaciones, etc.; promover una comunicación fuera de los límites áulicos entre el alumnado y el profesorado, o entre el alumnado.

El uso del aula virtual tiene ciertas ventajas en el proceso formativo:

a. Brinda actualización frecuente de contenidos.

b. Ofrece nuevas posibilidades de acción docente, como consultas en línea.

c. Permite realizar un seguimiento continuo del trabajo del alumnado.

d. Diversifica las actividades que el estudiantado puede realizar como participación en foros, creación de documentos, etc.

e. Es cómoda, porque ofrece la posibilidad de interacción a distancia y desde diversos lugares.

f. Introduce al estudiantado en el conocimiento de nuevas tecnologías.

\section{Metodología}

\subsection{Tipo de investigación}

Esta investigación tiene la característica de un estudio de tipo cualitativo, ya que no se pretende examinar los datos de manera numérica, sino que se busca describir las cualidades de un fenómeno observado que, en este caso, son las experiencias vividas por el estudiantado en el uso de algunas herramientas mediadas por TIC, en el aprendizaje de la fonética en el curso de Expresión Oral I LM- 2232 de las carreras de Bachillerato en Francés y Bachillerato en la Enseñanza del Francés. 


\subsection{Población}

Para esta investigación, participaron 26 personas. Sin embargo, no todas respondieron las encuestas de evaluación (anexos 1 y 2) de cada una de las herramientas utilizadas (Exelearning, Audacity y Aula Virtual de Apoyo de Mediación Virtual).

Para la evaluación de la herramienta Exelearning, esta fue respondida por 4 hombres $(18,18 \%)$ y 18 mujeres $(81,81 \%)$. El rango de edad de los hombres es de 21 a 25 años y el rango de edad de las mujeres es el siguiente: 13 (72,22\%) tienen entre 18 a 20 años, 4 (22,22\%) tienen entre 21 a 25 años y 1 tiene más de 31 años (5,55\%).

En cuanto a la evaluación de las herramientas Audacity y Aula Virtual de Apoyo, fue contestada por 6 hombres $(27,27 \%)$ y 16 mujeres $(72,72 \%)$. El rango de edad de los hombres es de 21 a 25 años y el rango de edad de las mujeres es el siguiente: $13(72,22 \%)$ tienen entre 18 a 20 años, 4 (22,22\%) tienen entre 21 a 25 años y 1 tiene más de 31 años (5,55\%).

\subsection{Descripción de los instrumentos y procedimiento}

La recolección de la información tuvo varias etapas. Primeramente, se confeccionaron los instrumentos para evaluar cada una de las herramientas empleadas en el curso de Expresión Oral I (anexos 1 y 2). Estos instrumentos consistían en preguntas acerca de información personal de los participantes, sobre si han utilizado algunas de estas herramientas, si su uso les permitió aprender mejor los contenidos del curso, si quisieran que se continuaran empleando en otros cursos, entre otras. Luego, se pasaron al estudiantado durante la última semana de mayo de 2013. Finalmente, se analizaron las respuestas y los comentarios.

\section{Resultados y su análisis. Análisis de la evaluación realizada por el estudiantado hacia las herramientas empleadas}

\subsection{Exelearning}

Esta herramienta se utilizó sobre todo para trabajar el contenido de los rasgos articulatorios de las vocales del francés, ya que permite utilizar imágenes para que el estudiantado observe la posición de los órganos articulatorios que intervienen en la producción de estos sonidos. Además, permite complementar la información con artículos en línea y repetición de los sonidos para que pueda familiarizarse con escucharlos, y a su vez, se puede incluir ejercicios teóricos sobre las características de estas vocales. 
Así se pudo organizar la secuencia didáctica en 3 grandes fases: una actividad de inicio a través de preguntas de reflexión para establecer los conocimientos que tiene el estudiantado acerca del tema; una actividad de desarrollo que se divide a su vez en varias partes (el concepto de vocal y sus características, el aparato fonador, la clasificación de las vocales, los tipos de vocales, el trapecio vocálico), y por último, una actividad de cierre con algunos ejercicios en línea con su realimentación.

De seguido se presenta el análisis de la encuesta respondida por el estudiantado acerca de su evaluación de las actividades realizadas con la herramienta.

Cabe destacar que ninguno de los participantes conocía la herramienta Exelearning, ni tampoco la había utilizado en los cursos de las carreras de Bachillerato en Francés y Bachillerato en la Enseñanza del Francés.

En cuanto a la pregunta acerca de si les gustaron las actividades desarrolladas en clase con la herramienta Exelearning, se obtuvo el siguiente resultado: el 100\% del estudiantado contestó que sí le había gustado. Las razones que dieron acerca de su preferencia por la herramienta Exelearning fueron las siguientes presentadas en el cuadro 1:

\section{Cuadro 1: Razones de la preferencia del uso de la herramienta Exelearning}

\begin{tabular}{|l|c|}
\hline \multicolumn{1}{|c|}{ Razones } & Porcentaje \\
\hline Interactividad la comprensión de la materia & $36,36 \%$ (8 personas) \\
\hline Facilitación de la la actividad & $27,27 \%$ (6 persones) \\
\hline Dinamismo de la presentación de la & $13,63 \%$ (3 personas) \\
\hline $\begin{array}{l}\text { Manera ordenada de la } \\
\text { actividad }\end{array}$ & $9,09 \%$ (2 personas) \\
\hline Lo completo del material & $13,63 \%$ (3 personas) \\
\hline $\begin{array}{l}\text { Otras razones, como la ruptura espacio- } \\
\text { tiempo, la efectividad, lo ilustrativo }\end{array}$ & $\begin{array}{c}13,63 \% \text { (cada una de las razones fue } \\
\text { mencionada por una persona) }\end{array}$ \\
\hline
\end{tabular}

Fuente: elaboración propia (2013)

Al analizar las razones dadas por el estudiantado, se puede ver que cumplen con las ventajas que ofrecen las TIC para el proceso formativo, ya que su uso logra fomentar e incrementar la motivación del estudiantado en el aula; ayuda a que este se involucre activamente en el proceso formativo, participando en la construcción de sus conocimientos; contribuye a la mejora de la comprensión de temas complejos a través de otros medios como el caso de uso de imágenes, de lecturas complementarias, de ejercicios interactivos, de ejemplos de pronunciación; además, hace que la materia no sea tan tediosa al presentarse, ya que se va haciendo por etapa y de manera guiada, y el estudiantado puede volver a revisar 
la materia vista en clase y retomarla para lograr producir aprendizaje, y es así como se consigue la ruptura espacio-tiempo.

En cuanto a la valoración de los elementos usados de la herramienta Exelearning, se puede decir que el 45,45\% apreció la forma de la presentación, como los colores, la organización del material; el $68,18 \%$ valoró el uso de imágenes para explicar los rasgos articulatorios de las vocales del francés, por la claridad de la posición de los órganos; el $81,81 \%$ apreció positivamente los ejercicios propuestos para trabajar los diferentes contenidos del objetivo de aprendizaje, ya que estos ofrecían realimentación del tema y guiaban al estudiantado en su proceso formativo; al 31,81\% le interesó, sobre todo, los links para complementar el tema con lecturas, grabaciones, entre otros, y así propiciar su autoaprendizaje; y por último, al 9,09\% le interesó los vínculos de acceso para encontrar ayuda y orientar hacia la reflexión del tema.

Con respecto a la claridad del objetivo trabajado con la herramienta Exelearning, el 86,36\% consideró que sí estuvieron más claros los contenidos abordados de esta manera. A continuación en el cuadro 2 se ilustran las razones por las cuales creyeron que la clase fue más clara al aplicar la estrategia mediada por TIC:

\section{Cuadro 2: Claridad del objetivo debido a la estrategia mediada por Exelearning}

\begin{tabular}{|l|l|}
\hline \multicolumn{1}{|c|}{ Razones } & \multicolumn{1}{|c|}{ Porcentaje } \\
\hline $\begin{array}{l}\text { Visualidad del contenido desarrollado por la utilización de } \\
\text { imágenes que representaban los órganos articulatorios para } \\
\text { la producción de las vocales del francés }\end{array}$ & $\begin{array}{l}45,45 \% \text { (10 personas mencionaron que esto les facilitó } \\
\text { la comprensión del contenido abordado y también les } \\
\text { ayudó a ubicar la posición de los órganos articulatorios } \\
\text { en su aparato fonador) }\end{array}$ \\
\hline $\begin{array}{l}\text { Realización de los ejercicios interactivos usando la } \\
\text { herramienta Exelearning }\end{array}$ & $\begin{array}{l}13,63 \% \text { (3 personas mencionaron que el hecho de } \\
\text { realizar ejercicios interactivos en donde recibían } \\
\text { realimentación, les facilitó la comprensión del } \\
\text { contenido abordado) }\end{array}$ \\
\hline Ejemplificación del contenido teórico & $\begin{array}{l}9,09 \% \text { (2 personas mencionaron que el hecho de que } \\
\text { el contenido teórico fuera explicado a través de } \\
\text { ejemplos, les facilitó una mejor comprensión de la } \\
\text { materia) }\end{array}$ \\
\hline $\begin{array}{l}\text { Disponibilidad del contenido para cada uno de los } \\
\text { aprendices }\end{array}$ & $\begin{array}{l}9,09 \% \text { (2 personas mencionaron que esto les ayudó a } \\
\text { retomar el contenido visto y a revisar cada contenido } \\
\text { fuera de la clase) }\end{array}$ \\
\hline $\begin{array}{l}\text { Otras razones, como el hecho de abordar más la parte oral, } \\
\text { la simplicidad de ver las cosas complejas explicadas a } \\
\text { través de imágenes, la interactividad para mantener la } \\
\text { atención y la concentración del estudiantado en el tema } \\
\text { abordado, la profundización del tema con otras lecturas y la } \\
\text { innovación en el curso por el hecho de que no se había } \\
\text { dutilizado esta herramienta en otros cursos. }\end{array}$ & \\
\hline
\end{tabular}

Fuente: elaboración propia (2013) 
Al analizar las razones brindadas por el estudiantado, se afirma que la implementación de la estrategia mediada por la herramienta Exelearning ha sido muy satisfactoria para el desarrollo de uno de los objetivos del curso, ya que ayudó a que el estudiantado tuviera una mejor comprensión de los contenidos y también a que pudiera trabajar de manera individual en su proceso formativo. Se observa un cambio de rol en el proceso formativo, ya que el docente media el proceso, facilitando los elementos necesarios para que el estudiantado logre aprendizaje y reflexione en su proceso formativo individual.

Sin embargo, hubo 3 personas que opinaron que el uso de la herramienta Exelearning no les ayudó a comprender claramente el objetivo desarrollado en clase, puesto que preferían más la clase tradicional, donde el docente explicaba la materia utilizando la pizarra o el libro de texto, sin emplear ningún tipo de link para evitar la dispersión de las ideas.

Esto muestra que todavía existe cierta resistencia de parte del estudiantado hacia el cambio de paradigma en la educación. Sin embargo, este cambio se puede dar exitosamente para el proceso formativo, ya que la gran mayoría ha manifestado de manera positiva su uso, y le ha ayudado a comprender mejor los contenidos desarrollados. Además, ha contribuido a que el estudiantado se implicara más en su proceso formativo, haciéndolo partícipe de la construcción de los conocimientos y de que pudiera construir los nuevos saberes a partir de los conocimientos adquiridos.

Con respecto al interés que tiene el estudiantado en emplear la herramienta Exelearning, el $86,36 \%$ de las personas aumentaron este sentimiento en cuanto a la clase. Esto se debe a las siguientes razones que se muestran en el cuadro 3 :

\section{Cuadro 3: Interés del estudiantado en la clase}

\begin{tabular}{|l|c|}
\hline \multicolumn{1}{|c|}{ Razones } & Porcentaje \\
\hline $\begin{array}{l}\text { Facilita la comprensión del contenido de la } \\
\text { clase }\end{array}$ & $36,84 \%$ (7 personas) \\
\hline $\begin{array}{l}\text { Organización del contenido en diferentes } \\
\text { etapas }\end{array}$ & $5,26 \%$ (1 persona) \\
\hline $\begin{array}{l}\text { Innovador de la herramienta por el hecho de } \\
\text { que es diferente y salir de la rutina }\end{array}$ & $15,78 \%$ (3 personas) \\
\hline $\begin{array}{l}\text { Presenta la clase de una manera más } \\
\text { dinámica e interactiva }\end{array}$ & $26,31 \%$ (5 personas) \\
\hline $\begin{array}{l}\text { Fomenta la práctica oral de los sonidos con } \\
\text { sus pares }\end{array}$ & $5,26 \%$ (1 persona) \\
\hline
\end{tabular}

Fuente: elaboración propia (2013) 
Al observar estas razones en el cuadro 3, se puede decir que la herramienta Exelearning contribuye a fomentar el interés del estudiantado en la clase, sobre todo por el hecho de que cambia totalmente la dinámica existente y ayuda a que este se involucre en su proceso formativo y así se puede lograr que participe también en el proceso del otro, potenciando el aprendizaje colaborativo entre pares. Sin embargo, algunas personas (9,09\%) no encontraron que esta herramienta haya contribuido a generar más interés en la clase, sino que lo mantuvieron. Esto puede hacer pensar que no siempre las herramientas mediadas por TIC logran despertar el mismo interés en todos, ya que cada quien construye su proceso formativo a su manera, y puede ser que para algunos estas herramientas generen más ansiedad por el aprendizaje, debido a su interactividad, dinamismo, etc., pero para otros puede ser que produzcan desinterés, por el hecho de que requieren un acompañamiento más humano.

Con respeto a su preferencia para que el docente siga empleando la herramienta en clase, el 90,90\% sugirió que se continúe usándola en clase, porque les despierta el interés, facilita su comprensión de los contenidos, existe mucha interactividad, es muy dinámica, existe una comunicación fluida entre el docente y el estudiantado, hace que la clase sea más entretenida, y por su carácter innovador.

Sin embargo, el 9,09\% manifestó que no les interesaba que el docente siguiera empleando esta herramienta, porque una mencionó que su aprendizaje no funcionaba de esta manera, y la otra, por el hecho de que le podía generar distracción por el uso de los links.

En cuanto a la última pregunta sobre si pudieron aprender mejor el contenido visto a través de esta herramienta, el 95,45\% manifestó que pudo desarrollar una mejor comprensión del contenido porque mantuvo su atención a lo largo de las lecciones, había imágenes y ejercicios interactivos que ayudaron a facilitar la comprensión del contenido, hizo que el contenido fuera presentado de manera más atractiva, dinámica e interactiva, había lecturas complementarias que completaban el tema en estudio, permitía revisar la información en otros momentos fuera de la clase, genera un aprendizaje más individualizado y personalizado con la ayuda docente. Sin embargo, el 4,55\% manifestó que esto le generó dispersión por la presencia de links.

En síntesis, la herramienta Exelearning ha sido de gran ayuda para desarrollar una secuencia didáctica de diferente manera, también de una forma más organizada, dinámica, interactiva y, a su vez, producir un aprendizaje más colaborativo y que el estudiantado se 
involucre personalmente en su proceso formativo, ya que facilita la independencia del estudiantado en su proceso y también le ayuda a construir sus conocimientos de otra manera. Esto obedece sobre todo a que existe un mayor aprendizaje significativo, porque se hace responsable de su proceso y tiene una mayor identificación con este.

Se puede ver que se logra un cambio de roles en el proceso formativo, donde el docente pasa de cumplir un papel activo, a ser un facilitador de este, y el estudiantado pasa de ser un ente pasivo a uno activo.

Sin embargo, todavía existe una cierta resistencia al cambio, ya que algunas personas manifestaron su poco interés hacia la herramienta y que no lograron encontrar una manera diferente de aprender, por el hecho de que esta le generó más dispersión en su proceso formativo.

Es así como se puede observar que las TIC tienen un doble papel en el proceso formativo: pueden contribuir positivamente o de manera negativa.

\subsection{Audacity}

Esta herramienta se empleó para que el estudiantado realice grabaciones de los sonidos y lecturas de textos, con el fin de que pudieran escucharse, realizar correcciones de pronunciación y enviarlas al docente para su revisión y realimentación.

De seguido se presenta el análisis de los resultados de la evaluación de la herramienta por parte del estudiantado.

Es importante mencionar que ninguno de los participantes conocía la herramienta Audacity, ni tampoco la había utilizado en los cursos de las carreras de Bachillerato en Francés y Bachillerato en la Enseñanza del Francés.

Todo el grupo respondió que la herramienta Audacity fue útil para el curso. A continuación en el cuadro 4, se detallan las diferentes razones: 


\section{Cuadro 4: Razones de la utilidad del programa Audacity}

\begin{tabular}{|c|c|}
\hline Razones & Porcentaje \\
\hline $\begin{array}{l}\text { Facilidad para realizar grabaciones de la } \\
\text { pronunciación de tipos de documentos } \\
\text { (palabras, lecturas, opiniones) y poder } \\
\text { revisarlas escuchándose de nuevo. }\end{array}$ & $\begin{array}{l}59,09 \% \text { ( } 13 \text { personas mencionaron que esta } \\
\text { herramienta es de gran utilidad por el hecho } \\
\text { de que se puede realizar fácilmente las } \\
\text { grabaciones de tipos de documentos y a su } \\
\text { vez, les permitía escucharse e identificar sus } \\
\text { errores para así corregirse antes de enviar la } \\
\text { grabación al docente para su realimentación.) }\end{array}$ \\
\hline $\begin{array}{l}\text { Permite hacer el trabajo en otros contextos que } \\
\text { no sean el aula y en otros tiempos que no sean } \\
\text { las horas lectivas. }\end{array}$ & $\begin{array}{l}9,09 \% \text { ( } 2 \text { personas dieron esta razón porque } \\
\text { la herramienta permite la ruptura del espacio- } \\
\text { tiempo, puesto que el aprendiz puede realizar } \\
\text { su aprendizaje en otros contextos y tiempo } \\
\text { fuera del aula, para aprovechar al máximo las } \\
\text { horas de clase, con el fin de realizar otras } \\
\text { tareas del curso.) }\end{array}$ \\
\hline $\begin{array}{l}\text { Ayuda a mejorar la pronunciación y a progresar } \\
\text { en el curso. }\end{array}$ & $\begin{array}{l}31,81 \% \text { ( } 7 \text { personas consideraron que esto } \\
\text { les ayudó a progresar en el curso, mejorando } \\
\text { su pronunciación, y concienciándose de su } \\
\text { propio proceso formativo.) }\end{array}$ \\
\hline $\begin{array}{l}\text { Motiva al estudiantado, por ser algo nuevo e } \\
\text { innovador en el curso, }\end{array}$ & $\begin{array}{l}4,56 \% \text { ( } 1 \text { persona dio esta razón por ser una } \\
\text { herramienta que no conocía y que por eso le } \\
\text { generó más motivación por la clase.) }\end{array}$ \\
\hline
\end{tabular}

Fuente: elaboración propia (2013)

Según las razones del estudiantado, las TIC, específicamente Audacity, es un complemento fundamental para el desarrollo del curso y, en este caso, para el aprendizaje de la fonética, ya que contribuye a crear independencia del aprendiz en su proceso formativo, por el hecho de que se involucra e interviene más en su propio proceso. Esto se refleja en que el estudiantado tome conciencia de su progresión y de su proceso de construcción de conocimientos. Además, fomenta su autoaprendizaje, como es el caso de que identifican sus errores y los mejora antes de enviar la grabación al docente para su realimentación. De esta manera, el docente cumple más bien un rol de facilitador y de guía en el proceso, en lugar de ser su protagonista, pues deja que el estudiantado participe de manera más activa en su proceso.

Con respecto a lo que más le gustó de la herramienta Audacity, el estudiantado mencionó las siguientes razones que se muestran en el cuadro: 
Cuadro 5: Razones por las cuales le gustó la herramienta Audacity

\begin{tabular}{|l|c|}
\hline \multicolumn{1}{|c|}{ Razones } & Porcentaje \\
\hline Facilidad de uso & $45,45 \%$ (10 personas) \\
\hline Poder escucharse a sí mismo & $13,63 \%$ (3 personas) \\
\hline Calidad de la grabación & $13,63 \%$ (3 personas) \\
\hline $\begin{array}{l}\text { Poder hacer sus propias correcciones (voz, } \\
\text { entonación, pronunciación, ritmo) al grabarse }\end{array}$ & $27,27 \%$ (6 personas) \\
\hline Comodidad & $9,09 \%$ (2 personas) \\
\hline
\end{tabular}

Fuente: elaboración propia (2013)

Como se observa, las estrategias mediadas por herramientas de TIC son una gran ayuda para el desarrollo de la clase, ya que su uso puede motivar al estudiantado a tener más interés en la clase y fomenta su participación en el proceso formativo.

En cuanto a si el uso de Audacity ayudó al estudiantado a mejorar su pronunciación, el $77,27 \%$ manifestó que pudo aprender a pronunciar mejor los sonidos del francés, ya que se podía escuchar nuevamente las grabaciones para identificar los errores con el fin de corregirlos, tomar conciencia de estos, mejorarlos y fomentar la autocorrección. Se puede ver como su uso ayuda a crear independencia del aprendiz en su proceso formativo, y a que este se responsabilice también de su proceso. Sin embargo, el 22,72\% dijo que no le ayudó a mejorar su pronunciación, puesto que la herramienta no hace las correcciones del caso, sino que el aprendiz debe identificar por sí mismo sus errores y corregirlos para luego enviar la grabación final al docente para su revisión y realimentación de cada caso, para que el estudiantado escuche la pronunciación correcta.

Esta situación refleja claramente el rol del docente como mediador del proceso formativo, ya que planea las actividades para que logre en cada etapa adquirir nuevos conocimientos y mejorarlos continuamente. Por eso, el hecho de ver que el estudiantado manifiesta que la herramienta no le facilita el aprendizaje de la pronunciación, porque esta no hace las correcciones cuando se equivoca, hace pensar que en realidad es errónea su inquietud, ya que si logra identificar sus errores y corregirlos antes de mandar la grabación al docente, se está produciendo aprendizaje en él. Esta forma de aprendizaje tal vez no es la acostumbrada por los modelos tradicionales de enseñanza, en donde se recibe inmediatamente las correcciones, sin haber pasado por un proceso de toma de consciencia de su propio aprendizaje, y de que se responsabilice de su proceso para que el docente cumpla verdaderamente un rol de mediador, y no como el que maneja los saberes y los transmite. 
Es así como las TIC cumplen con ese papel de cambio de roles en el proceso formativo, ya que involucran más al estudiantado y relevan el papel del docente a facilitador.

Con respecto a la pregunta sobre si es necesario que el docente siga fomentando el uso de Audacity en la clase, el 100\% del estudiantado se manifestó positivamente, ya que la herramienta es útil para mejorar la pronunciación, para tomar conciencia de su proceso de aprendizaje, ayudar a identificar los errores para autocorregirse, es fácil de utilizar, rompe los espacios temporales establecidos, es interactiva, cambia la dinámica tradicional de una clase de lengua, ayuda al estudiantado más tímido o con más miedo de hablar en público a desenvolverse, y ayuda a perder el miedo de pronunciar mal, por el hecho de que se puede corregir y así mejorar su pronunciación.

\subsection{Aula virtual de apoyo de la plataforma Mediación Virtual}

En cuanto a esta herramienta, se usó para colocar materiales complementarios del curso, ejercicios en línea, foros de discusión y de dudas, envío de grabaciones de lecturas.

A continuación se presentan los resultados de la evaluación hecha por el estudiantado acerca de la herramienta.

Es importante decir que ninguno de los participantes conocía la herramienta de aula virtual, ni la había utilizado en los cursos de las carreras de Bachillerato en Francés y Bachillerato en la Enseñanza del Francés.

Al $100 \%$ del estudiantado le gustó el uso del Aula Virtual de Apoyo para el curso de Expresión Oral I. A continuación en el cuadro 6 se detallan las razones por las cuales esta herramienta tuvo un impacto positivo en el alumnado: 


\section{Cuadro 6: Razones por las cuales le gustó la herramienta}

\begin{tabular}{|l|l|}
\hline \multicolumn{1}{|c|}{ Razones } & \multicolumn{1}{|c|}{ Porcentaje } \\
\hline Ruptura del espacio y tiempo & $\begin{array}{l}\text { El } 50 \% \text { (11 estudiantes) del alumnado dio } \\
\text { esta razón, ya que la plataforma de Aula } \\
\text { Virtual de Mediación Virtual estaba siempre } \\
\text { disponible para que pudiera revisar los } \\
\text { materiales que había de los diferentes temas } \\
\text { del curso; también se podía enviar las tareas } \\
\text { en línea, consultar e interactuar con el } \\
\text { docente en cualquier momento y lugar, y } \\
\text { además, compartir las dudas con los otros } \\
\text { estudiantes del grupo. }\end{array}$ \\
\hline $\begin{array}{l}\text { Ayuda a progresar en el curso por el apoyo } \\
\text { complementario de la materia. }\end{array}$ & $\begin{array}{l}\text { El 40,90\% (9 estudiantes) del alumnado } \\
\text { mencionó esta razón, porque al encontrar } \\
\text { materiales complementarios del curso, como } \\
\text { lecturas, ejercicios, videos, esto ayudó a } \\
\text { progresar y a su vez a fomentar un } \\
\text { aprendizaje más significativo, ya que podía } \\
\text { consultar el material que le interesaba } \\
\text { reforzar, según las necesidades. }\end{array}$ \\
\hline $\begin{array}{l}\text { Rompe con las maneras tradicionales de la } \\
\text { enseñanza de una segunda lengua. }\end{array}$ & $\begin{array}{l}4,57 \% \text { (1 estudiante) manifestó que era algo } \\
\text { muy diferente a lo que se empleaba en el } \\
\text { primer año de la carrera. }\end{array}$ \\
\hline Facilidad de su uso & $\begin{array}{l}\text { El 4,57\% (1 estudiante) mencionó que era } \\
\text { una plataforma de muy fácil uso y acceso. }\end{array}$ \\
\hline
\end{tabular}

Fuente: elaboración propia (2013)

Al analizar estas razones, se puede ver que las ventajas de las TIC contribuyen enormemente al proceso formativo del estudiantado y estas nuevas formas rompen esquemas tradicionales, ya que el espacio y el tiempo de clase cambian totalmente, y se da la desaparición de estas barreras. Esto crea un entorno virtual que genera un proceso formativo más abierto y flexible, ya que las posibilidades de aprendizaje del estudiantado no se limitan solo a un entorno presencial y cercano a su realidad, sino que puede seguir aprendiendo en otros espacios y momentos. Además, existe una gran mejora de la comunicación entre el estudiantado y el profesorado, ya que no se restringe solo a un espacio y tiempo de clase, sino que va más allá de esto y así se favorece un proceso formativo más dinámico e interactivo.

Con respecto a lo que le gustó más al estudiantado del Aula Virtual de Apoyo, el $36,36 \%$ manifestó que los foros, porque les permitían aclarar dudas sobre la materia vista, interactuar con el docente y otros compañeros de la clase acerca de alguna duda sobre la materia, tener al docente disponible en horario fuera de clase y en cualquier momento de la semana para las dudas o preguntas sobre lo visto en clase; el 50\% mencionó las lecturas, 
prácticas y materiales complementarios de la materia, porque podían revisar otros materiales para completar la materia vista en clase y esto les ayudaban a complementar lo trabajado en el aula; el $22,72 \%$ dijo que la disponibilidad del material en todo momento, para consultar, revisar, retomar todo lo visto en clase en otro momento y espacio; y por último, el 13,63\% señaló que todo, ya que cada elemento disponible en la plataforma contribuyó a su proceso formativo.

En cuanto a la utilidad del Aula Virtual de Apoyo para el aprendizaje de la fonética, el $95,45 \%$ se manifestó positivamente, porque tenía la accesibilidad y la disponibilidad del material en todo momento, por lo cual esto les ayudó a progresar y a mejorar en el curso; había materiales complementarios como lecturas, prácticas, videos, etc., que les ayudaban a comprender y a complementar la materia vista en clase; la comodidad de realizar las prácticas o las lecturas en cualquier momento de la semana y fuera del horario de clase; la posibilidad de enviar dudas y recibir respuestas del docente en cualquier momento; la personalización y la individualización del proceso de enseñanza-aprendizaje, ya que cada persona podía revisar el material a su ritmo y de nuevo pedir al docente la aclaración de dudas o explicaciones de materia en otros momentos fuera de la clase; ayuda a ahorrar el tiempo de clase, ya que se podía realizar más prácticas sobre los diferentes temas del curso en otros momentos y recibir la realimentación del docente, y de esta manera se aprovechaba más el tiempo de clase para tareas como transcripciones fonéticas; lo atractivo del recurso, puesto que existe más interactividad y rompe esquemas tradicionales de enseñanza; y por último, por la facilidad de su uso. Solo una estudiante dijo que el Aula Virtual de Apoyo no fue útil para el aprendizaje de la fonética, puesto que no lo usó para este fin.

Con respecto a la necesidad de que el docente siga empleando el Aula Virtual de Apoyo para el siguiente curso, el 100\% del alumnado se manifestó positivamente. A continuación en el cuadro 7 se detallan las razones de esta necesidad. 
Cuadro 7: Razones por las cuales se necesita seguir usando el Aula Virtual de Apoyo

\begin{tabular}{|l|c|}
\hline \multicolumn{1}{|c|}{ Razones } & Porcentaje \\
\hline Gran ayuda para complementar el curso. & $40,90 \%$ (9 estudiantes) \\
\hline $\begin{array}{l}\text { Accesibilidad, la disponibilidad, la facilidad y la } \\
\text { efectividad de encontrar la información en } \\
\text { cualquier momento }\end{array}$ & $40,90 \%$ (9 estudiantes) \\
\hline $\begin{array}{l}\text { Facilidad de comunicarse con el docente en } \\
\text { cualquier momento }\end{array}$ & $18,18 \%$ (4 estudiantes) \\
\hline $\begin{array}{l}\text { Enriquecimiento de las posibilidades de } \\
\text { aprendizaje a través de nuevas formas no } \\
\text { tradicionales }\end{array}$ & $9,09 \%$ (2 estudiantes) \\
\hline $\begin{array}{l}\text { Necesidad de cambiar las formas tradicionales } \\
\text { de aprendizaje }\end{array}$ & $4,54 \%$ (1 estudiante) \\
\hline Experiencia positiva de su uso & $4,54 \%$ (1 estudiante) \\
\hline
\end{tabular}

Fuente: elaboración propia (2013)

Al observar las razones dadas por el estudiantado, se puede apreciar que el Aula Virtual de Apoyo fue de gran utilidad y una necesidad para complementar el curso, para implementar otras formas de aprendizaje dadas fuera del aula y así crear otros vínculos de comunicación entre docente y estudiante, en distintos espacio y momento.

Con respeto a la pregunta de si el uso de la aplicación Aula Virtual de Apoyo le facilitó aprender mejor el contenido de la clase, el 86,36\% manifestó de manera positiva, ya que fue de gran apoyo y complemento para la clase presencial, por el material y la cantidad de datos que estaba a su disposición, como imágenes, videos, lecturas, prácticas, tareas facultativas; permitía revisar los contenidos vistos en clase en otros momentos; la claridad y el orden en que se encontraba disponible el material. Sin embargo, el 13,63\% mencionó que esta herramienta no le ayudó a generar un mejor aprendizaje de los contenidos del curso, ya que el mayor aprendizaje se produjo en el aula.

En relación con las otras herramientas que se quiere que el docente utilice en el Aula Virtual de Apoyo para el próximo curso, el estudiantado manifestó la necesidad de implementar las lecciones en forma de video de los temas más complejos, para repasar y revisar la materia vista en clase, de utilizar más prácticas interactivas, de proponer más lecturas de apoyo y de libros de práctica para reforzar los contenidos vistos, sobre todo para efectuar las transcripciones fonéticas.

Esta necesidad que tiene el estudiantado sobre la manera de reforzar el contenido de las transcripciones fonéticas por medio de las TIC, es difícil de realizar, ya que la plataforma 
de Mediación Virtual no tiene compatibilidad con el programa que se usa para las transcripciones fonéticas, ni tampoco puede leer los símbolos fonéticos. Por lo tanto, el estudiantado no puede hacer transcripciones directamente en línea y recibir inmediatamente la realimentación del caso, sino que debe hacer las transcripciones a mano y enviar el documento escaneado al docente, para su revisión y realimentación.

En cuanto a las herramientas usadas en el aula virtual que consideran que no son necesarias para el curso, el 13,63\% manifestó que las lecturas y los ejercicios en línea, pero el $86,36 \%$ dijo que todo era muy necesario e importante para el desarrollo del curso, por lo tanto no le quitaría ningún tipo de elemento.

En síntesis, se puede considerar que el Aula Virtual de Apoyo para el eje de la fonética del curso de Expresión Oral I de las carreras de Bachillerato en Francés y Bachillerato en la Enseñanza de Francés es una necesidad importante, ya que cambia las formas tradicionales del aprendizaje de la fonética, haciendo que el estudiantado se involucre constante y activamente en su proceso formativo, bajo la mediación pedagógica dada por el docente y generando esta ruptura de barreras espaciales y temporales.

Lo anterior provoca un cambio en las formas tradicionales de enseñanza-aprendizaje, ya que los conocimientos y la información no se quedan solo presentes en el espacio y el tiempo de la clase, sino que están disponibles en cualquier lugar y momento para que el estudiantado pueda accederlos. Además, el docente no termina su labor en el momento de la clase, sino que debe estar disponible para el estudiantado en otros periodos. Así puede contribuir a fomentar un proceso formativo más individualizado y personalizado, ya que puede conocer mejor las necesidades del estudiantado en su curso, y acompañarlo más en su proceso.

\section{Conclusiones y recomendaciones}

Como conclusiones, el desarrollo de esta estrategia mediada por las herramientas Exelearning, Audacity y Aula Virtual, en el eje de la fonética del curso de Expresión Oral I de las carreras de Bachillerato en Francés y Bachillerato en Enseñanza del Francés, ha aportado una experiencia muy enriquecedora para el autor, por las razones que se mencionarán.

El desafío de experimentar y la pérdida de miedo para cambiar la dinámica tradicional del eje de la fonética, en una clase de lengua extranjera, donde el docente ocupaba un papel primordial en el aula y el estudiantado tenía un rol secundario, hicieron que los roles se 
intercambiaran, ya que este último tuvo un papel más activo en el aula. Esto se logró gracias a la incorporación de las TIC en el aula, que permitieron que el alumnado tuviera mayor protagonismo y asumiera de manera más autónoma su proceso formativo. Sin embargo, hizo también que el docente cambiara su técnica para transmitir conocimientos, ya que en lugar de hacerlo de esta manera tradicional, tuvo que buscar una forma de mediar, orientar y facilitar la materia, para generar un aprendizaje más significativo en el estudiantado y para que pudiera construir sus conocimientos.

Es preciso mencionar que este giro de paradigma genera también un cambio en la forma tradicional de planear las actividades para cada lección, ya que implica una dedicación mayor de tiempo, requiere de un diseño previo bien estructurado que permita organizar el contenido, seleccionar las actividades, planificar las interacciones y esbozar la evaluación. Además, es muy necesario que el material presentado al estudiantado sea atractivo y que tenga significado para este, con el fin de que logre ligar los conocimientos previos con los nuevos y así propiciar un aprendizaje significativo.

Esta nueva forma de proceso de aprendizaje y de enseñanza rompe las barreras tradicionales, ya que el espacio y el tiempo no se reducen al aula y al periodo lectivo, sino que es totalmente flexible y abierto. Esto obedece al hecho de que el estudiantado pueda consultar, revisar, realizar, etc., todas las actividades que tiene a su disposición en la plataforma. Sin embargo, cambia la dinámica de comunicación entre el docente y el estudiantado, ya que no se queda solo en el espacio del aula o de consultas en la oficina, sino que implica una disponibilidad más grande, en tanto estaría sujeto a evacuar las dudas y preguntas del estudiantado en cualquier momento y lugar. De esta manera, se logró una mejora en la comunicación entre las distintas partes participantes, favoreciendo e incrementando el intercambio de la información y la colaboración entre las partes.

Cabe decir que al incorporar estas herramientas de las TIC en el curso de fonética, se fomentó un aprendizaje más personalizado e individualizado en el estudiantado, pues al disponer de los contenidos desarrollados en la clase en la plataforma, cada estudiante pudo retomar los temas, consultar las nuevas fuentes de la información según su necesidad y también progresar de acuerdo con su ritmo de aprendizaje, y así plantear las preguntas al docente de algún punto que todavía generaba dudas. Esto produjo gran autonomía en su proceso formativo. Sin embargo, es fundamental que cada estudiante tuviera conciencia de su responsabilidad en su propio proceso y, además, de tener el acompañamiento del docente 
para guiarlos a lo largo de este y brindar las realimentaciones de cada caso para facilitarle su proceso de construcción de conocimientos.

Es importante fomentar otras estrategias para generar efectivamente un aprendizaje más personalizado e individualizado en el estudiantado, como el uso de las tutorías, para apoyarlo de manera más sistemática, con el fin de favorecer una mejor comprensión de los problemas que enfrenta el alumnado.

Otro punto esencial del uso de TIC en el eje de la fonética del curso de Expresión Oral I, es que estas herramientas generaron motivación en el alumnado, puesto que le permite aprender la materia de forma más atractiva, amena, divertida, investigando de una forma sencilla. Sin embargo, pueden generar también estrés y dispersión. Esta situación tuvo lugar sobre todo en la primera sesión, cuando se desarrolló la estrategia didáctica empleando la herramienta Exelearning, porque algunas personas indicaron dificultades para abrir el documento en su computadora, porque esta no era compatible con Internet Explorer, sino solamente con Mozilla. Este es un elemento que se debe tomar en cuenta para la próxima vez que se planee una lección usando las herramientas de las TIC, y así evitar ese tipo de circunstancia en el aula.

Otra razón importante que deja el uso de las TIC en el aula es el hecho de disponer del tiempo de clase para realizar tareas como ejercicios de transcripción fonética y prácticas orales, mientras antes era destinado a la práctica de lectura de cada estudiante. Con la implementación de la herramienta Audacity, esta actividad de lectura individual en clase ya no era tan necesaria, pues el estudiantado podía grabar la lectura hecha y enviarla al docente para su realimentación y corrección. Esta manera de abordar la lectura era más enriquecedora para el alumnado, ya que le permite escucharse, autocorregirse, identificar sus dificultades, mejorar su lectura antes de enviarla al docente y a este, trabajar de forma más individualizada con cada estudiante, reiterándole las partes por mejorar.

Otro elemento fundamental al implementar el uso de las TIC en el aula, es el hecho de que esto conllevaría a replantear otra forma de evaluación que no sea la tradicional prueba, ya que al introducir el uso de las TIC en el aula, muchas veces la prueba escrita no sería el instrumento idóneo para medir los conocimientos construidos por el estudiantado, sino que se debería pensar en alternativas para evaluar estos conocimientos. Sin embargo, generar estos cambios es muy complicado, sobre todo para los cursos colegiados, donde las evaluaciones se aplican igual para todos los grupos, como es el caso del curso de Expresión Oral I. 
En cuanto a las recomendaciones, es preciso seguir actualizándose en el manejo de las TIC y tratar de implementar otras herramientas en el curso, para potenciar todas las ventajas que ofrecen. Sin embargo, no se debe abusar de estas, por cuanto son un apoyo para el proceso formativo: no reemplazan al docente, sino que cambian la manera tradicional de impartir una clase y hacen que el proceso sea más dinámico y que el estudiantado participe más en él.

Además, es necesario tomar en cuenta el contexto en donde se busca implementar estas herramientas, ya que no siempre se puede contar con todos los recursos ni tampoco con el interés general, por lo tanto, es conveniente adaptarse a las circunstancias y las necesidades del estudiantado.

En el caso de las carreras de Bachillerato en Francés y Bachillerato en la Enseñanza del Francés, es pertinente que se incorporen las TIC en los otros cursos como medio de apoyo a la docencia, y cambiar el paradigma tradicional de la enseñanza de lenguas extranjeras, ya que como se vio en la evaluación hecha por el estudiantado acerca de las herramientas utilizadas en el curso, el impacto fue muy positivo y se sugiere que se sigan empleando. Sin embargo, se requiere, por supuesto, capacitar al personal docente en su uso y en la manera de intervenir en el proceso de la mediación de los conocimientos a través de las TIC.

Por último, se puede destacar la gran experiencia adquirida tras el uso de las herramientas de las TIC en el curso de Expresión Oral I, en el eje de la fonética, tanto para el docente como para el estudiantado, ya que hubo una mayor flexibilidad en el proceso formativo, un cambio de roles, más autonomía en el estudiantado por el hecho de involucrarse en su proceso, entre otros. Todavía queda mucho camino por recorrer para potenciar y aprovechar las bondades que estas herramientas puedan aportar al mejoramiento del proceso formativo y, sobre todo, para fomentar este cambio de paradigma en la enseñanza de las lenguas extranjeras en Costa Rica, con el fin de lograr que el estudiantado tenga un rol más activo en el aula y participe en su proceso de construcción de conocimientos.

\section{Referencias}

Adell, Jordi. (1991). Tendencias en educación en la sociedad de las tecnologías de la información. EDUTEC, Revista Electrónica de Tecnología Educativa, (17). Recuperado de http://edutec.rediris.es/Revelec2/revelec28/revelec28.html 
Álvarez, Alfredo. (2004). Las TIC en el aprendizaje del francés lengua extranjera. Revista de Educación, (335), 497-512.

Basque, Josianne. (2005). Une réflexion sur les fonctions attribuées aux TIC en enseignement universitaire. Revue internationale des technologies en pédagogie universitaire, 2(1), 3041. Recuperado de http://www.ritpu.org//MG/pdf/ritpu 0201 basque-2.pdf

Beauné, Aurélie. (2011). Quelles utilisations des TICE pour l'apprentissage du français langue étrangère au niveau A1.1. ?. (Mémoire de Master 2). Paris, Francia : Université ParisDescartes.

Chacin, Julia. (2006). Uso de Internet en la enseñanza de lenguas extranjeras. Trujillo: Universidad de Trujillo. Recuperado de http://www.saber.ula.ve/bitstream/123456789/28814/1/articulo3.pdf

Chacón, Silvia. (2012). Orientaciones didácticas y técnicas para el diseño básico de aulas virtuales. San José: Universidad de Costa Rica.

Cladellas, Ramón y Castelló, Antoni. (2010). Aportes y perjuicios de las TIC’s a la educación. Psicología Básica, Evolutiva y de la Educación, s.f.

Fernández, Inmaculada. (2010). Las TICs en el ámbito educativo. Eduinnova, (21), 1-9.

Ferro, Carlos, Martinez, Ana Isabel y Otero, Maria del Carmen. (julio 2009). Ventajas del uso de las TICs en el proceso de enseñanza-aprendizaje desde la óptica de los docentes universitarios españoles. Revista Electrónica de Tecnología Educativa, (29), 1-12. Recuperado de http://edutec.rediris.es/Revelec2/revelec28/revelec28.html

Malagón, Mario y Frías, Yicel. (2008). La mediación como potencialidad de las tecnologías de la información y las comunicaciones en los procesos de enseñanza-aprendizaje. Cuba: Universidad de Pinar del Río.

Palomar, María José. (2009). Ventajas e inconvenientes de las TIC en la docencia. Revista Digital Innovación y Experiencias Educativas, 45, 1-8.

Perreault, Nicole (2005). Rôle et impact des TIC sur l'enseignement et l'apprentissage au collégial-I. Repère: Pédagogie Collégiale, 1-14. 


\section{Anexos}

\section{Anexo 1}

\section{Evaluación de la herramienta "Exelearning", por parte de estudiantes}

Objetivo de la encuesta: evaluar la actividad desarrollada en la clase.

Favor marcar con una "X".

1. Edad: $18-20$ años $21-25$ años $26-30$ años más de 31 años

2. Sexo M $\mathrm{H}$

3. ¿Ha usado la herramienta Exelearning en los cursos de Francés Integrado I y Francés Integrado II?
Sí
No (Pasar a la pregunta 5)

4. ¿Para qué ha usado la herramienta Exelearnig en los cursos de Francés Integrado I y Francés Integrado II?

5. ¿Le gustó la actividad desarrollada en clase con la herramienta ExeLearning?

Sí No

¿Por qué?

6. ¿Qué le gustó más de la herramienta utilizada en clase?

Los colores Las imágenes Los ejercicios Los links Otros (cuáles) Especifique:

7. ¿Sintió que la clase estuvo más clara utilizando esta herramienta?

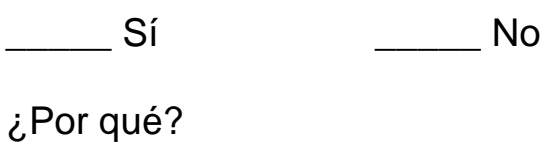


8. ¿Tiene más interés en la clase?

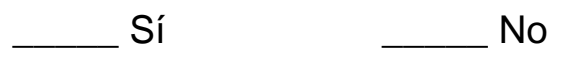

¿Por qué?

9. ¿Quiere que el o la docente siga usando esta herramienta en clase?

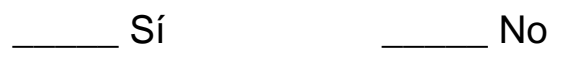

¿Por qué?

10. ¿Aprendió mejor el contenido de la clase con el uso de "Exelearning"?

Sí

No

¿Por qué? 


\section{Anexo 2}

\section{Evaluación de las herramientas "Audacity" y Aula Virtual de Apoyo de METICS, por parte de estudiantes}

Objetivo de la encuesta: evaluar la herramienta Audacity y el Aula Virtual en el curso de Fonética.

Favor marcar con una "X".

1. Edad: $18-20$ años $21-25$ años $26-30$ años más de 31 años

2. Sexo $\mathrm{M}$ $\mathrm{H}$

3. ¿Ha usado la herramienta Audacity en los cursos de Francés Integrado I y Francés Integrado II?

Sí No (Pasar a la pregunta 5)

4. ¿Para qué ha usado la herramienta Audacity en los cursos de Francés Integrado I y Francés Integrado II?

5. ¿Le pareció que la herramienta fue útil para el curso de fonética?

Sí No

¿Por qué?

6. ¿Qué le gustó más de la herramienta Audacity utilizada en clase?

7. ¿Sintió que la herramienta Audacity le ayudó a mejorar su pronunciación? Sí No

¿Por qué?

8. ¿Quiere que el o la docente siga usando esta herramienta en clase? Sí No

¿Por qué? 
9. ¿Ha usado el Aula Virtual (Mediación Virtual) en los cursos de Francés Integrado I y Francés Integrado II?

Sí

No (Pasar a la pregunta 11)

10. ¿Para qué ha usado el Aula Virtual en los cursos de Francés Integrado I y Francés Integrado II?

11. ¿Le gustó el uso del Aula Virtual de Apoyo para el curso de Fonética?

Sí _ No

¿Por qué?

12. ¿Qué le gustó más del Aula Virtual de Apoyo para el curso de Fonética? ¿Por qué? (foro, presentaciones, videos, lecturas, etc.)

13. ¿Sintió que el Aula Virtual de Apoyo fue útil para el aprendizaje de la fonética?

Sí No

¿Por qué?

14. ¿Quiere que el o la docente siga usando el Aula Virtual de Apoyo en el siguiente curso? Sí No

¿Por qué?

15. ¿Aprendió mejor el contenido de la clase con la ayuda del Aula Virtual de Apoyo? Sí No

¿Por qué?

16. ¿Qué otras herramientas del Aula Virtual quiere que el docente use en el próximo curso de Fonética?

17. ¿Qué herramientas (foros, lecturas, presentaciones, ejercicio en línea, etc.) del Aula Virtual considera que no son necesarias para el curso de Fonética? 